\title{
Dependence of critical porosity on pore geometry and pore structure and its use in estimating porosity and permeability
}

\author{
Suryo Prakoso ${ }^{1} \cdot$ Pudji Permadi $^{2} \cdot$ Sonny Winardhi ${ }^{3} \cdot$ Taufan Marhaendrajana $^{2}$
}

Received: 20 June 2017 / Accepted: 26 November 2017 / Published online: 18 December 2017

(c) The Author(s) 2017. This article is an open access publication

\begin{abstract}
It is well recognized that the wave velocity is not only influenced by its constituent materials but also by the details of the rock bulk. This situation may bring about data points of P-wave velocity $V_{\mathrm{p}}$ measured on a large number of rock samples against either porosity or permeability of the frequently scattered although certain trends may exist. This paper presents the results of a study by employing rock samples on which $\phi, k$, and $V_{\mathrm{p}}$ are measured in attempt to characterize critical porosity $\phi_{\mathrm{c}}$ and its relation to other rock properties. The approach used in this study is the use of Kozeny equation. The equation is believed to account for all parameters influencing absolute permeability of porous media. A mathematical manipulation done on the equation has resulted in a power law equation that relates pore geometry $\sqrt{ }(k / \phi)$ to pore structure $k / \phi^{3}$. Three different sets of sandstone amounting totally to as many as 716 samples were provided in this study. The properties measured are $\phi, k$, and $V_{\mathrm{p}}$, and grain size. For each sandstone data set, at least there are nine groups of the rock samples obtained. When $V_{\mathrm{p}}$ is plotted against $\phi$, it is found that each group of each sandstone data set has both its own $\phi_{\mathrm{c}}$ and an excellent relation of $\phi$, $V_{\mathrm{p}}$, and $\phi_{\mathrm{c}}$. Furthermore, combining all the basic equation for $V_{\mathrm{p}}$, Kozeny equation, and the empirical relation for porosity results in a model equation to predict permeability. In conclusion, for the sandstones employed, $\phi_{\mathrm{c}}$ is a specific property of a group of rocks having a similar pore geometry.
\end{abstract}

Keywords Pore geometry $\cdot$ Pore structure $\cdot$ P-wave velocity $\cdot$ Porosity $\cdot$ Permeability $\cdot$ Critical porosity

\section{Introduction}

Several studies have been conducted to define the relationship between velocity and porosity. The relationship between velocity and porosity for the entire porosity range is not linear as indicated by Wyllie et al. (1956). The velocity value will be maximum at zero porosity that describes mineral velocity and the value of velocity will be minimum when the solid material becomes less and as pore space increases as demonstrated by Raymer et al. (1980). For a porosity greater

Suryo Prakoso

suryo_prakoso@trisakti.ac.id

1 Petroleum Engineering, Faculty of Earth and Energy Technology, Universitas Trisakti, Jakarta, Indonesia

2 Petroleum Engineering, Faculty of Mining and Petroleum Engineering, Institut Teknologi Bandung, Bandung, Indonesia

3 Geophysical Engineering, Faculty of Mining and Petroleum Engineering, Institut Teknologi Bandung, Bandung, Indonesia than $47 \%$, the relationship between velocity and porosity is not linear. Han et al. (1986) showed that the velocity and porosity have a linear relationship and can be separated based on the volume of clay. Furthermore, Nur et al. (1995) shows that sandstone, limestone, dolomite and igneous rocks have different characteristics so that each has its own critical porosity. The value of the critical porosity is determined by the type of mineral, rock texture, and diagenetic processes after deposition (Mavko et al. 2009). Prakoso et al. (2016) shows that the relationship between $\mathrm{P}$-wave velocity with pore geometry and pore structure can be grouped based on the similarity of pore geometry and pore structure. Rock samples with similar pore geometry and pore structure will have their own group referred to as rock type and have different relationships between velocity and porosity.

Several other researchers have arranged the relationship between P-wave velocity and permeability by incorporating the influence of pore geometry. Klimentos (1991) shows that the empirical relationship between P-wave velocity and permeability is directly proportional and influenced by the clay content, the specific surface area and micro porosity. 
Prasad (2003) used the hydraulic unit to arrange the relationship between P-wave velocity and permeability. Fabricius et al. (2007) shows that the ratio relationship of $V_{\mathrm{p}} / V_{s}$ in dry rocks is strongly influenced by the specific surface area and demonstrated that permeability can be predicted from the relationship between the specific surface area, $V p / V s$ and porosity. Weger and Eberli (2009) showed that the relationship between porosity, permeability and $V_{\mathrm{p}}$ is influenced by micro porosity, pore network complexity, and pore size.

This paper presents the influence of the rock type on the relationship between P-wave velocity and both porosity and permeability. Rocks grouping was based on the similarity of pore geometry and pore structure. It is evident that each group of rocks has a different critical porosity value. Critical porosity value is not only influenced by lithology of rock as shown by Nur et al. (1995) but also by complexity of pore geometry and pore structure of rocks. By grouping the rocks based on their rock type, the relationship between porosity, permeability and P-wave velocity can be established. Furthermore, these relationships can be used to estimate porosity and permeability based on the P-wave velocity.

\section{Methods and data}

\section{Rock grouping}

In the context of the concept of critical porosity, it might be helpful to consider the relationship between the materials composing the rocks and the pores architecture formed. A perfect and simplest example of rocks is clean sandstones, typically employed by Nur et al. (1995). Unfortunately, many reservoir rocks are not that simple. However, Mavko et al. (2009) found that rock texture and diagenetic processes could play an important role in determining the critical porosity. It has been recently found that rock samples originating from both similar depositional environments and similar diagenetic processes all have similar pores architecture (Wibowo and Permadi 2013). El-Khatib (1995) also shows that rock samples which have similar capillary pressure curve should have similar pore size distributions so that it will have similar pore geometry and pore structure. Thus, it will have the same value of tortuosity $(\tau)$ and irreducible water saturation $\left(S_{w i}\right)$. The similarity in pores architecture is manifested by the similarity in the pore shape and tortuosity. The combination of these two pore attributes is well known as the Kozeny constant (Kozeny 1927). The only difference among the rock samples having a similar Kozeny constant is the pore size in terms of mean hydraulic radius. The wellknown Kozeny equation can be expressed as follows:
$\left(\frac{k}{\phi}\right)^{0.5}=\phi\left(\frac{1}{\left(F_{\mathrm{s}} \tau S_{b}^{2}\right)}\right)^{0.5}$

where $k$ is permeability, $\phi$ is porosity, $F_{\mathrm{s}}$ is shape factor, $\tau$ is tortuosity, and $S_{\mathrm{b}}$ is specific internal surface area. $(k / \phi)^{0.5}$ describes characteristics of the pore geometry and $\left(k / \phi^{3}\right)$ represents the pore structure which is a function of the internal parameters of the pore such as shape factor $F_{\mathrm{s}}$, tortuosity $\tau$, and the specific surface area $S_{\mathrm{b}}$. Equation 1 can be written in the form of power law equation as follows:

$\left(\frac{k}{\phi}\right)^{0.5}=a\left(\frac{k}{\phi^{3}}\right)^{b}$

Plotting $(k / \phi)^{0.5}$ on $Y$ axis against $\left(k / \phi^{3}\right)$ on $X$ axis on a $\log -\log$ graph will produce a straight line with maximum slope of line $b=0.5$ for capillary tube systems. This means the value of $b 0.5$ indicates a perfect rounded pore shape. For natural porous media, the value of $b$ is less than 0.5 . The more complex the pore shape of the rock, the lower the $b$ value where $a$ is a constant that is interpreted as a correction factor for volumetric fluid flow efficiency for irregular pore systems (Permadi and Wibowo 2013).

\section{Dry bulk modulus and critical porosity}

Nur et al. (1995) modified the Voigt bound by using the concept of critical porosity $\phi_{\mathrm{c}}$. Critical porosity $\phi_{\mathrm{c}}$ is defined as the value of porosity that separates behavior of acoustic wave velocity in porous media on the load-bearing frame and fluid bearing suspension.

$B=\left(1-\frac{\phi}{\phi_{\mathrm{c}}}\right) B_{\mathrm{m}}+\left(\frac{\phi}{\phi_{\mathrm{c}}}\right) B_{\mathrm{c}}$

Modifications on the Voigt bound using critical porosity (Nur et al. 1995) can also be applied to shear modulus (Mavko et al. 2009) which can be written as follows:

$\mu=\left(1-\frac{\phi}{\phi_{\mathrm{c}}}\right) \mu_{\mathrm{m}}+\left(\frac{\phi}{\phi_{\mathrm{c}}}\right) \mu_{\mathrm{c}}$

where $B$ and $\mu$ is bulk and shear modulus, $B_{\mathrm{m}}$ and $\mu_{\mathrm{m}}$ is bulk and shear modulus of mineralogy, $B_{\mathrm{c}}$ and $\mu_{\mathrm{c}}$ is bulk and shear modulus at critical porosity and $\phi_{\mathrm{c}}$ is critical porosity. For dry conditions, the value $B_{\mathrm{c}}=0$ so that Eq. 3 becomes:

$B=\left(1-\frac{\phi}{\phi_{\mathrm{c}}}\right) B_{\mathrm{m}}$

Equation 5 can be arranged into a linear equation as follow; 
$\frac{B}{B_{m}}-1=-\frac{\phi}{\phi_{c}}$

Equation (6) says that plotting $B$ and $\mu$ against $\phi$ will form a straight line with a slope of $-1 / \phi_{\mathrm{c}}$ and will intersect the $Y$ ordinate at $B=B_{\mathrm{m}}$ and $\mu=\mu_{\mathrm{m}}$.

\section{Data used}

This study used three data sets of sandstones from three different basins that have variations in porosity, permeability and P-wave velocity. Data sets 1 and 2 were obtained from the publication by Prakoso et al. 2016. Data set 1 are sandstones of the North West Java basin, dominated by finegrained to coarse-grained. The porosity range is $6.76-36.9 \%$, while the permeability data range is $0.12-5713 \mathrm{mD}$ and volume clay is below $20 \%$. The data set 2 sandstones were from the Kutai Basin, dominated by fine-grained to coarsegrained. The porosity range is $4.5-36.9 \%$, while the permeability range is $0.05-4504 \mathrm{mD}$ and volume clay is below $10 \%$. The data set 3 sandstones were from the South Sumatra basin, dominated by fine-grained to coarse-grained. The porosity range is $6.76-36.9 \%$, while the permeability range is $0.12-5713 \mathrm{mD}$ and volume clay is below $10 \%$. As much as 716 cores of data were used including routine core data analysis, sedimentology analysis and dry P-wave velocity $V_{\text {pdry. }}$. The routine core data analysis included permeability, porosity and lithology descriptions. Sedimentology data analysis included petrography (thin section) and XRD. $\mathrm{P}$-wave and S-wave velocity data was obtained from measurements using SonicViewer-Sx equipped with piezoelectric transducer to measure the $\mathrm{P}$-waves and $\mathrm{S}$-wave. Measurements were taken on dry conditions, at atmospheric pressure (1 atm or $0.101 \mathrm{Mpa})$ and room temperature $\left(25^{\circ} \mathrm{C}\right)$. Prior to measurement, core samples were dried at $150^{\circ} \mathrm{F}$ for $12 \mathrm{~h}$.

\section{Results and discussion}

\section{Grouping data into rock type}

The relationship between P-wave velocity and bulk modulus with both pore geometry and pore structure was obtained by grouping the rocks by the similarity of microscopic geology feature. This grouping of rocks was done by using a rock type chart published by Wibowo and Permadi (2013) and Wibowo (2014). Figure 1 shows the result of the grouping of data set 1 where the data that fall on the same line were interpreted as having similar microscopic geological feature, which is herein after referred to as rock type. The dominant factors affecting each group of rocks characterized by the

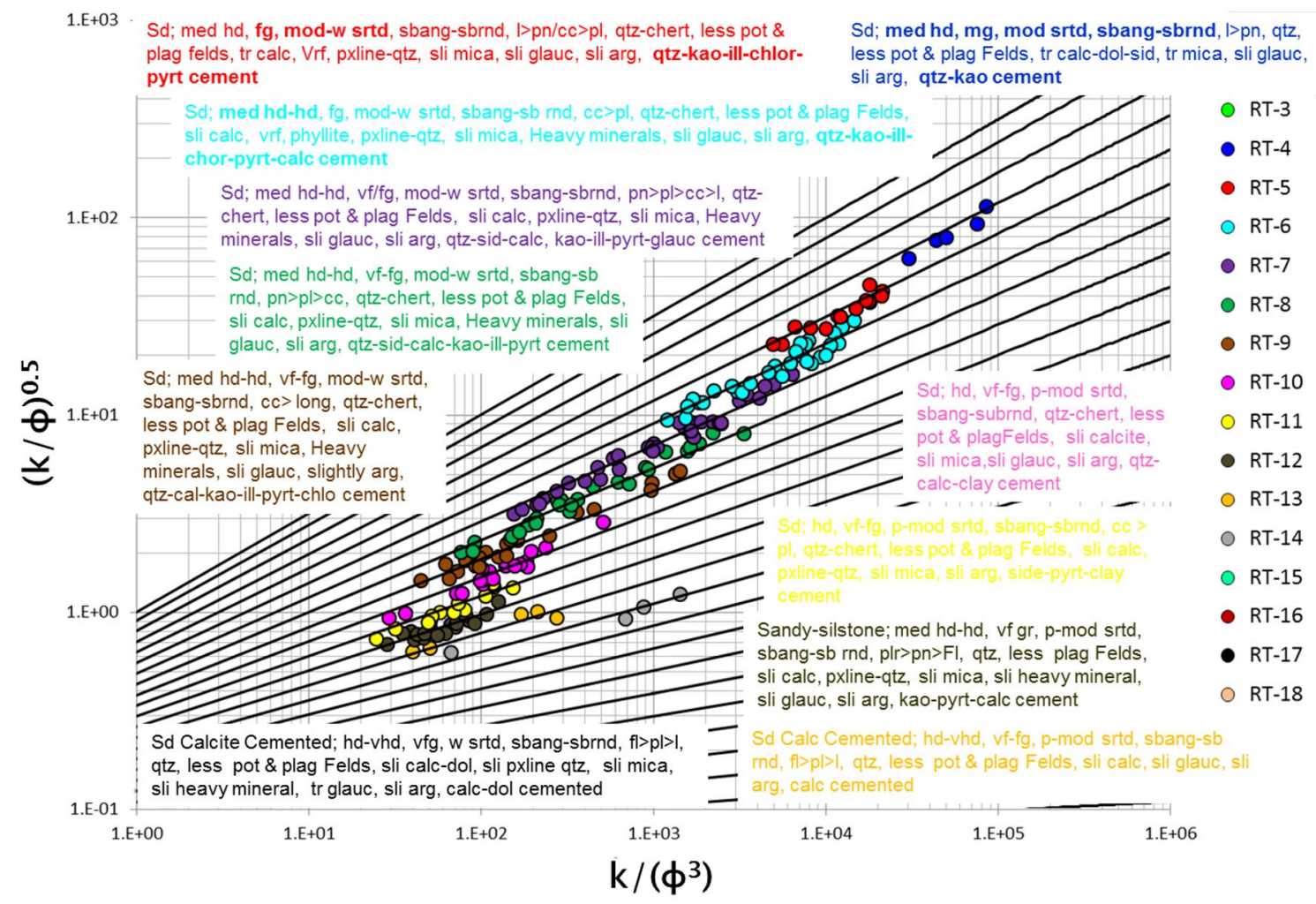

Fig. 1 Identification of the rock type based on pore geometry and pore structure for data set 1 (Prakoso et al. 2016)

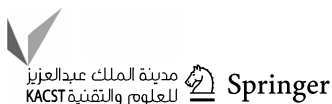


similarity of the rock texture include grain size, grain sorting, grain angularity and roundness. The diagenetic influence on each rock type was indicated by the difference in hardness. The greater the hardness, the lower the quality of the rock type. Rock quality is also affected by the type of cement whereby good-quality rock types tend to be dominated by quartz and kaolinite cement. Rock types with lower quality, the type of cement is dominated by carbonate minerals including among others, calcite and dolomite. Besides that, the increase in the volume of clay will also tend to lower the quality of rock. Good-quality rock types tend to have a low clay volume. Increase in the volume of clay will tend to lower the quality of rock type.

\section{Relation rock type, dry P-wave velocity and critical porosity}

This study demonstrated that the P-wave velocity in sandstones can specifically be characterized by the similarity of the pore geometry and pore structure. P-wave velocity is a function of the bulk modulus so that the bulk modulus should also be grouped by the similarity of pore geometry and pore structure. In this study, the value of the dry bulk modulus $\left(B_{\text {dry }}\right)$ was obtained based on the measurement of P-wave velocity. Bulk modulus dry curve $\left(B_{\text {dry }}\right)$ were calculated using the data $V_{\text {pdry }}, V_{\text {sdry }}$ and density $(\rho)$ using Eqs. 7 and 8 as follow:

$V_{\mathrm{p}}=\sqrt{\frac{B+(4 / 3) \mu}{\rho}}$

$V_{\mathrm{s}}=\sqrt{\frac{\mu}{\rho}}$

The assumptions used are homogeneous and elastic medium, while the theoretical curve of the dry bulk modulus of each rock type is calculated by using the equation Nur et al. (1995) (Eq. 5). Each rock type is characterized by different critical porosity values. The assumptions used in the calculation of theoretical bulk modulus dry curve $\left(B_{\text {dry }}\right)$ are as follows:

- The rocks are composed by the dominant minerals quartz.

- Assumed bulk modulus mineral modulus $\left(B_{\mathrm{m}}\right) 37 \mathrm{Gpa}$

Figure 2 shows a plot of the $B_{\text {dry }}$ data against $\phi$ of the three sandstone data sets. In one rock type, there was similarity of microscopic geological feature characterized by the similarity of textures and diagenetic processes. Thus, in one rock type, there is similar pore geometry and pore structure. Due to the similarities in pore geometry and pore structure, each rock type will have its own bulk modulus relationships pattern with porosity (Fig. 2). Relationship trends of the bulk modulus with porosity of each rock type will likely intersect the $X$-axis at certain value of porosity hereinafter referred to as critical porosity $\left(\phi_{c}\right)$. Therefore, Nur critical porosity model (Eq. 6) can be easily applied to extrapolate bulk modulus starting from bulk modulus of minerals $\left(B_{\mathrm{m}}\right)$ with zero porosity together with the bulk modulus data to the point of critical porosity $\left(\phi_{\mathrm{c}}\right)$ at zero bulk modulus $\left(B_{\mathrm{c}}\right)$. The relationship between dry bulk modulus (Eq. 6) against the porosity for each rock group will form a linear straightline. Thus, the magnitude of the critical porosity value can be defined by a simple linear equation. Hence, each rock type will have a different critical porosity value. It can be seen that the magnitude of the critical porosity value depends on the rock type. The better the rock type has a smaller slope and the greater critical porosity values (Table 1). The use of a linear trend causes the critical porosity values obtained to be smaller than the largest porosity values within a single rock type. This anomaly occurs mainly in good-quality rock type that has a limited amount of data.

In one rock type, there are similarities of Kozeny constant even with a different specific surface area (Wibowo and Permadi 2013). Thus, in a rock type, there are similarities of tortuosity and pores shape. However, as shown in Table 1, although the rock type is the same (e.g., rock type 5), there is a difference in critical porosity values for data sets 1,2 and 3. Despite the rock type being the same, the data sets 1 , 2 and 3 were formed from different sedimentation and diagenetic processes so that it results in a relationship between velocity and porosity with different critical porosity value. This influence of the sedimentation process is shown by the difference in hardness, grain size and clay volume that affect the value of the porosity and permeability of each data set (Table 2). It can be seen in Table 2 that even with the same rock type, there are differences in range of porosity and permeability values. Data set 1 has a relatively greater porosity than the data sets 2 and 3, but it has a lower permeability. In addition to the factor of hardness and grain size, the data sets 2 and 3 tend to have lower clay volume compared to the data set 1 . If the bulk modulus is only affected by porosity as shown in Eq. 6, the difference in the range of porosity values in the same rock type for the data set 1,2 and 3 are the main factors that cause the difference in the value of critical porosity.

Therefore, a relationship can be formed between the P-wave velocity and porosity for each rock type based on its value of critical porosity (Fig. 3). The orange line is calculated using critical porosity model Nur by assuming the maximum porosity of 0.476 for sandstones with a simple cubic packing of perfect rounded grains. One may expect that natural porous rocks with various complex textures and cementation would deviate from the behavior of simple grains shape and arrangement. The value of $V_{\text {pdry }}$ dotted line 

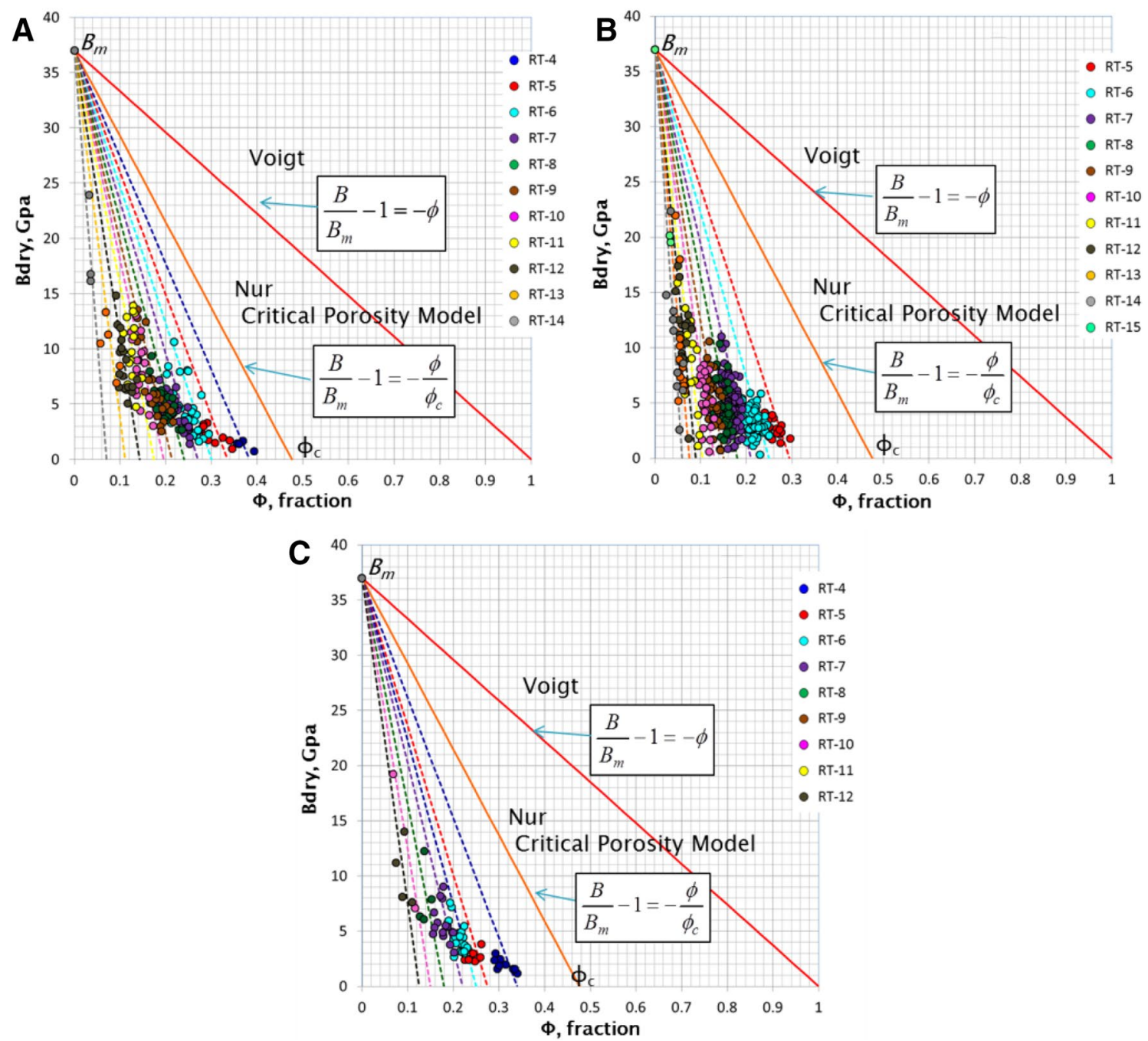

Fig. 2 Plot $B_{d r y}$ versus porosity for each rock type compared with Voigt model for data set 1 (a), 2 (b) and 3 (c) (colored dashed line is best fit Nur critical model for each rock type)

Table 1 The relationship between porosity with bulk modulus and critical porosity value for each rock

\begin{tabular}{|c|c|c|c|c|c|c|}
\hline \multirow{2}{*}{$\begin{array}{l}\text { Rock } \\
\text { Type }\end{array}$} & \multicolumn{2}{|l|}{ Data Set 1} & \multicolumn{2}{|l|}{ Data Set 2} & \multicolumn{2}{|l|}{ Data Set 3} \\
\hline & Equation & $\phi_{\mathrm{c}}$, fraction & Equation & $\phi_{c}$, fraction & Equation & $\phi_{\mathrm{c}}$, fraction \\
\hline 4 & $B=-96.425 \phi+37$ & 0.3837 & - & - & $B=-110.45 \phi+37$ & 0.3350 \\
\hline 5 & $B=-110.45 \phi+37$ & 0.3350 & $B=-125.42 \phi+37$ & 0.2950 & $B=-132.14 \phi+37$ & 0.2800 \\
\hline 6 & $B=-123.33 \phi+37$ & 0.3000 & $B=-48.00 \phi+37$ & 0.2500 & $B=-148 \phi+37$ & 0.2500 \\
\hline 7 & $B=-137.04 \phi+37$ & 0.2700 & $B=-176.19 \phi+37$ & 0.2100 & $B=-185 \phi+37$ & 0.2000 \\
\hline 8 & $B=-154.17 \phi+37$ & 0.2400 & $B=-205.56 \phi+37$ & 0.1800 & $B=-205.56 \phi+37$ & 0.1800 \\
\hline 9 & $B=-173.06 \phi+37$ & 0.2138 & $B=-246.94 \phi+37$ & 0.1498 & - & - \\
\hline 10 & $B=-189.74 \phi+37$ & 0.1950 & $B=-283.7 \phi+37$ & 0.1304 & $B=-246.67 \phi+37$ & 0.1500 \\
\hline 11 & $B=-212.25 \phi+37$ & 0.1743 & $B=-356.09 \phi+37$ & 0.1039 & - & - \\
\hline 12 & $B=-259.22 \phi+37$ & 0.1427 & $B=-414.06 \phi+37$ & 0.0894 & $B=-296 \phi+37$ & 0.1250 \\
\hline 13 & $B=-333.4 \phi+37$ & 0.1110 & $B=-486.94 \phi+37$ & 0.0760 & - & - \\
\hline 14 & $B=-523.98 \phi+37$ & 0.0706 & $B=-616.67 \phi+37$ & 0.0600 & - & - \\
\hline
\end{tabular}


Table 2 Different ranges of porosity, permeability and $V_{p d r y}$ of rock type 5 for the data sets 1,2 and 3

\begin{tabular}{|c|c|c|c|c|c|c|c|c|c|}
\hline \multirow[t]{2}{*}{ RT } & \multicolumn{3}{|l|}{ Data set 1} & \multicolumn{3}{|l|}{ Data set 2} & \multicolumn{3}{|l|}{ Data set 3} \\
\hline & $\phi$ fraction & $k \mathrm{mD}$ & $V_{p d r y} \mathrm{~m} / \mathrm{s}$ & $\phi$ fraction & $k \mathrm{mD}$ & $V_{p d r y} \mathrm{~m} / \mathrm{s}$ & $\phi$ fraction & $k \mathrm{mD}$ & $V_{p d r y} \mathrm{~m} / \mathrm{s}$ \\
\hline \multirow[t]{4}{*}{5} & 0.346 & 273 & 1219 & 0.260 & 1348 & 1880 & 0.225 & 1846 & 2249 \\
\hline & 0.294 & 298 & 1707 & 0.241 & 856 & 2116 & 0.235 & 1505 & 2360 \\
\hline & 0.291 & 525 & 2063 & 0.248 & 1704 & 1943 & 0.247 & 1147 & 2111 \\
\hline & 0.308 & 236 & 1418 & 0.277 & 4162 & 1713 & 0.259 & 1192 & 1998 \\
\hline
\end{tabular}
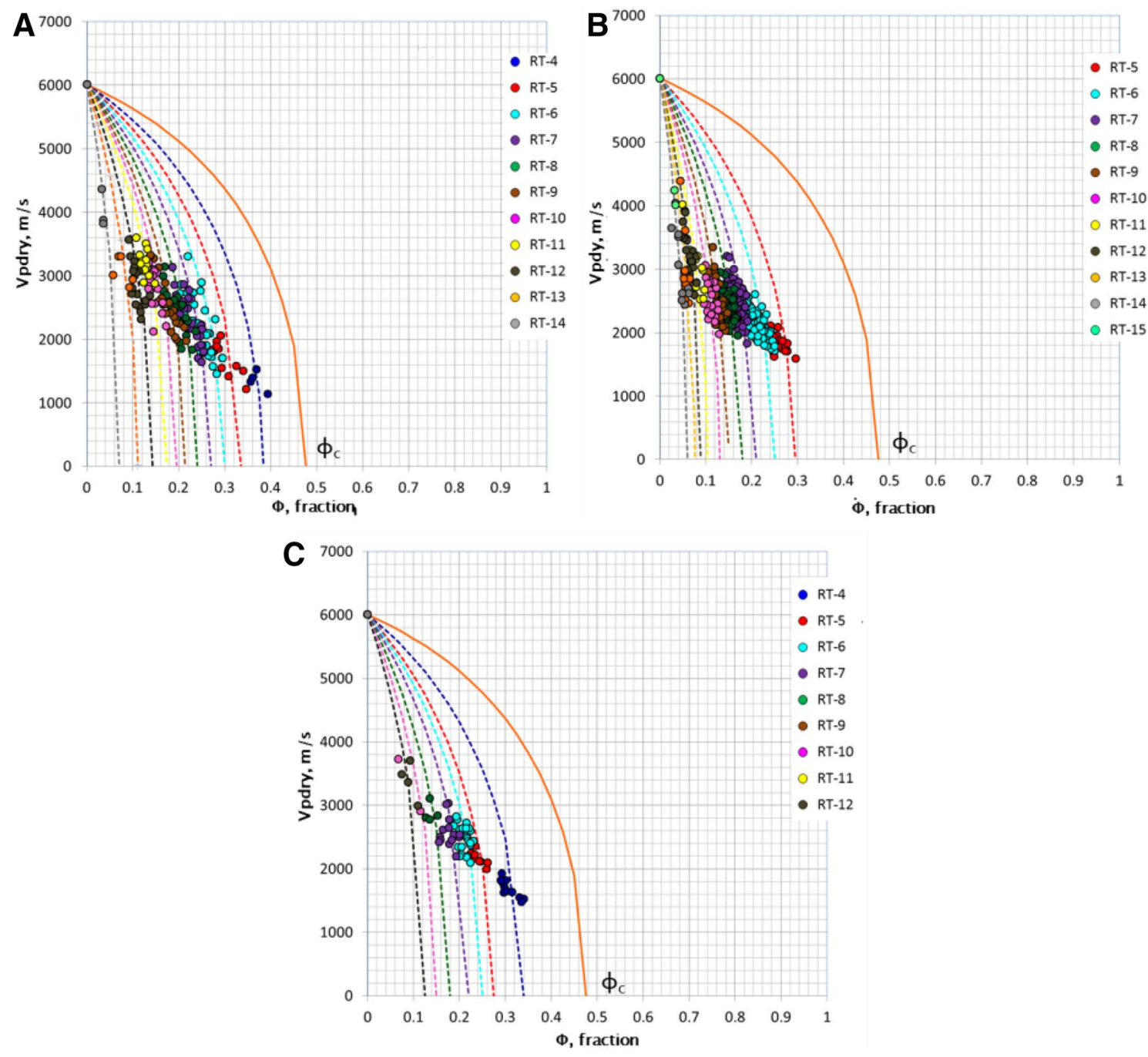

Fig. 3 Plot $V_{p d r y}$ versus porosity for each rock type for data set 1 (a), 2 (b) and 3 (c) (colored dashed line is derived with different critical porosity value for each rock type)

is calculated with the critical porosity value obtained when the value of the bulk modulus of each of the rock group is zero. As can be seen in Fig. 3, the data points for each rock type tend to form its own cluster.

Some data points of neighboring rock types overlap and some data points of a certain rock type fall on the trend line of a next rock type. These indicate that some members of two closest neighbors may have the same porosity but different pore geometry and structure. Such behavior implies that the dry bulk modulus and P-wave velocity of the sandstones are not only controlled by porosity but also by pore geometry and structure. In other words, dry bulk modulus and $\mathrm{P}$-wave velocity of the sandstones in relation to porosity are specifically characterized by the similarity in pore geometry and structure. This results is a certain critical porosity value for a given rock type. 


\section{Relationship of specific surface area, pore geometry and P-wave velocity}

The Kozeny equation (1927) can be formulated to obtain the value of specific surface area. Kozeny equation for permeability can be written as follows:

$k=0.9869 \frac{c \phi^{3}}{S_{\mathrm{b}}^{2}}$

So that the specific surface area relative to bulk volume can be written as:

$S_{\mathrm{b}}=\left(\frac{c \phi^{3}}{k / 0.9869}\right)^{0.5}$ where $S_{\mathrm{b}}$ is specific surface area (1/micron), $k$ permeability (darcy) while $c$ is a Kozeny's constant that is a function of the shape factor $F_{\mathrm{s}}$, tortuosity $\tau$. The values of $c$ are calculated using the Mortensen et al. (1998) approach for a simple 3D linear penetrating tubes model. The Mortensen equation is written as follows:

$c=\left(4 \cos \left(\frac{1}{3} \arccos \left(\phi \frac{8^{2}}{\pi^{3}}-1\right)+\frac{4}{3} \pi\right)+4\right)^{-1}$

Figure 4 shows that specific surface area $\left(S_{\mathrm{b}}\right)$ and grain size have an inversely proportional relationship. Large grain size will tend to have lower specific surface area $\left(S_{\mathrm{b}}\right)$. The large grain sizes will also tend to increase the hydraulic radius $(k / \phi)^{0.5}$. Thus, the value of the specific surface area $\left(S_{\mathrm{b}}\right)$ can be correlated with the hydraulic radius $(k / \phi)^{0.5}$. The same rock type may have similar pore shape but different pore sizes so that the difference is in value of the specific

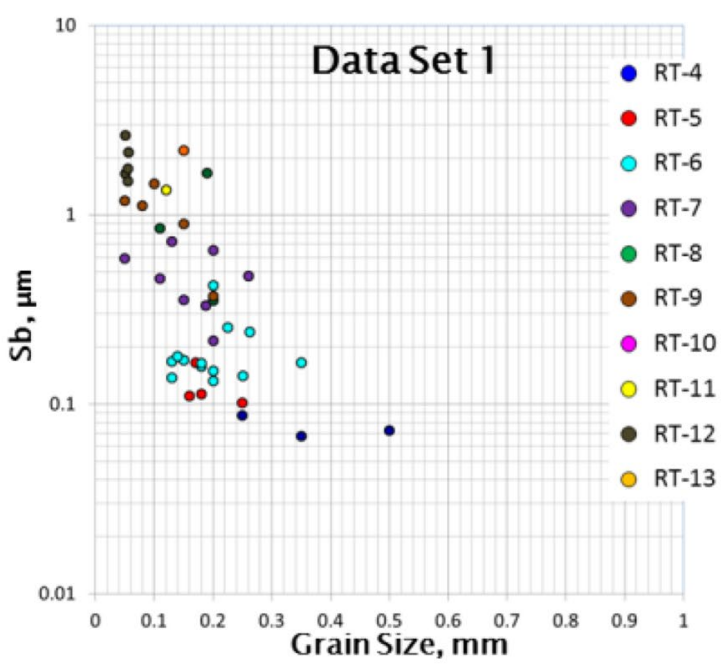

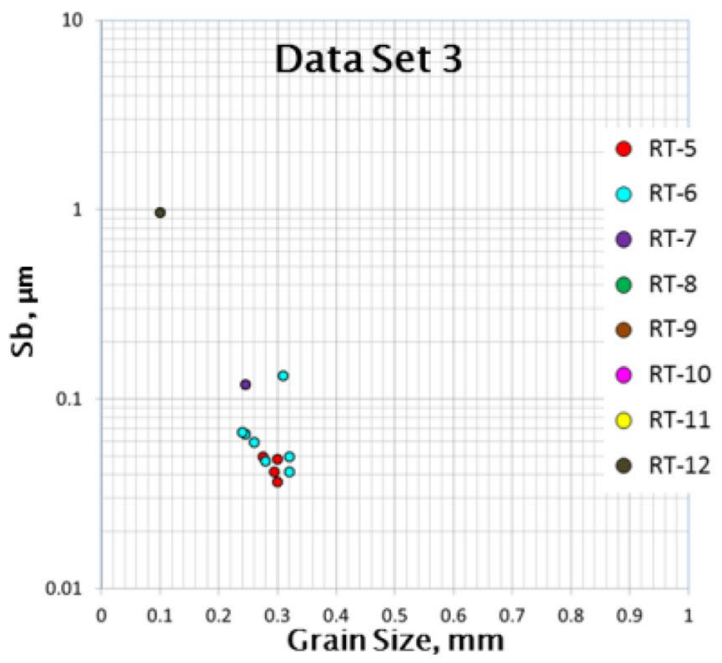

Fig. 4 Relationship of grain size with specific surface area 

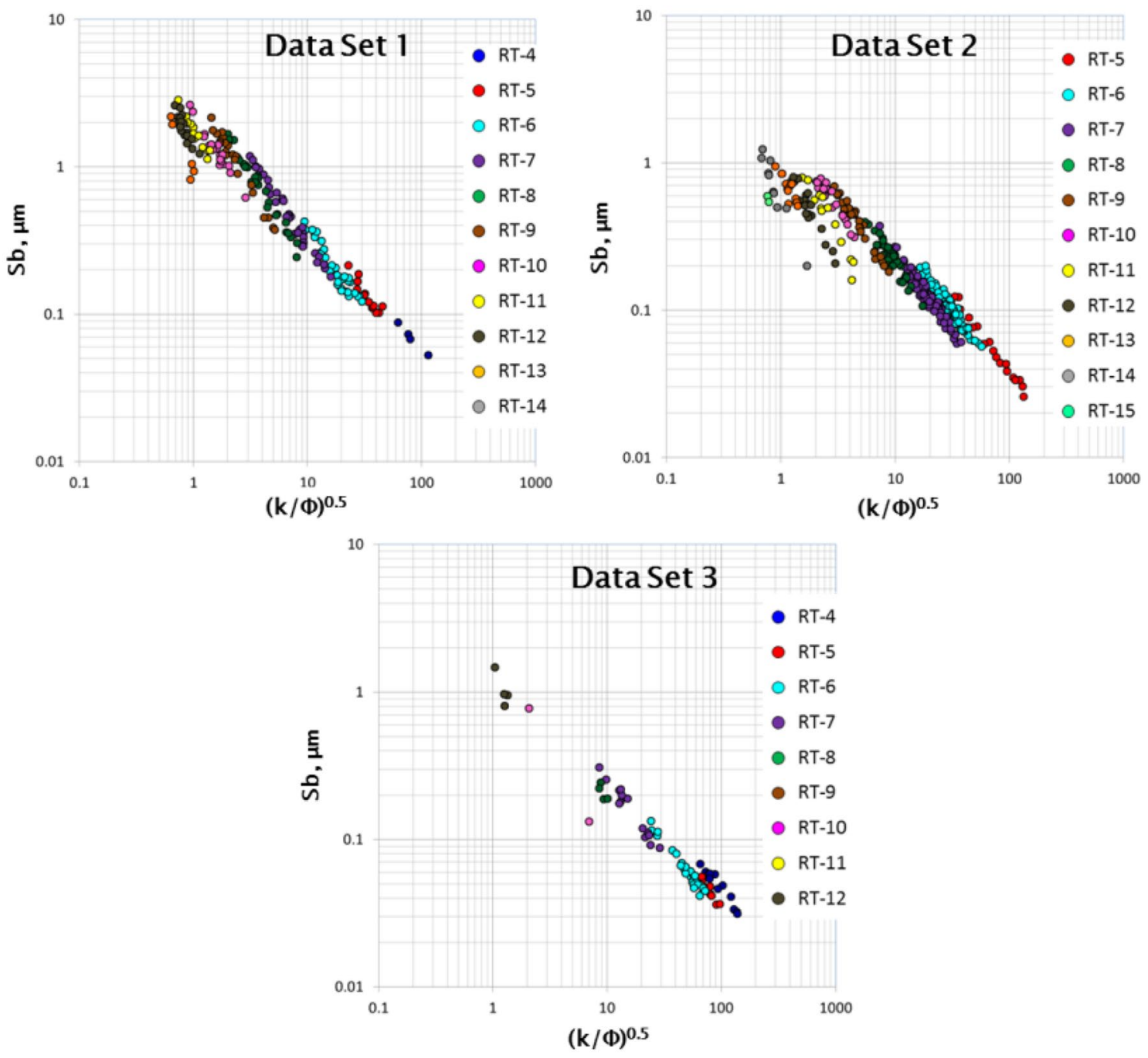

Fig. 5 Relationship of $(k / \phi)^{0.5}$ with specific surface area

surface area. For the same rock type, large grain size will tend to have large hydraulic radius $(k / \phi)^{0.5}$ so that the value of the specific surface area will be low (Fig. 5). This is because per unit of bulk volume, large grain size will form large pore spaces but fewer in number compared to the small grain size. Small pore sizes will have porosity greater than the large pore size, but it has a lower permeability. So that the small pore sizes will have a large value of the specific surface area than large pore size.

Large hydraulic radius will tend to increase the value of $V_{\text {pdry }}$ (Prakoso et al. 2016). Large hydraulic radius composed by large grain size has a lower $S_{\mathrm{b}}$ value and will increase $V_{\text {pdry }}$ value (Fig. 6). Thus, the increase in value of $V_{\text {pdry }}$ correlated with $S_{\mathrm{b}}$ values. For the same rock type, the greater the value of $(k / \phi)^{0.5}$ indicates the large value of hydraulic radius or larger pore size so that the specific area value is low. Here, we can see a clear relationship between the P-wave velocity and the specific surface area $S_{b}$. The relationship between
$S_{\mathrm{b}}$ and $V_{\text {pdry }}$ for each rock type is arranged in the form of an exponential equation as follows:

$S_{\mathrm{b}}=a e^{-b V p d}$

As discussed earlier, large grain sizes will increase the $\mathrm{P}$-wave velocity. The large grain sizes tend to form large pore spaces but are fewer in number compared to the small grain size. This makes rocks with a large grain size to have a low specific surface area. Thus, a low specific surface area will tend to increase the P-wave velocity. Weger and Eberli (2009) also showed that a large pore size and simple pore shape will have low perimeter over area $(P O A)$ value and high $\mathrm{P}$-wave velocity value. This is shown by Eq. 12 which describes that the relationship between $S_{\mathrm{b}}$ and $V_{\mathrm{p} d r y}$ is inversely proportional. The value of constants $a$ and $b$ in Eq. 12 for each rock type can be seen in Table 3. At the $V_{\text {p } d r y}$ value 0 then $S_{\mathrm{b}}$ value is the same with the constant 

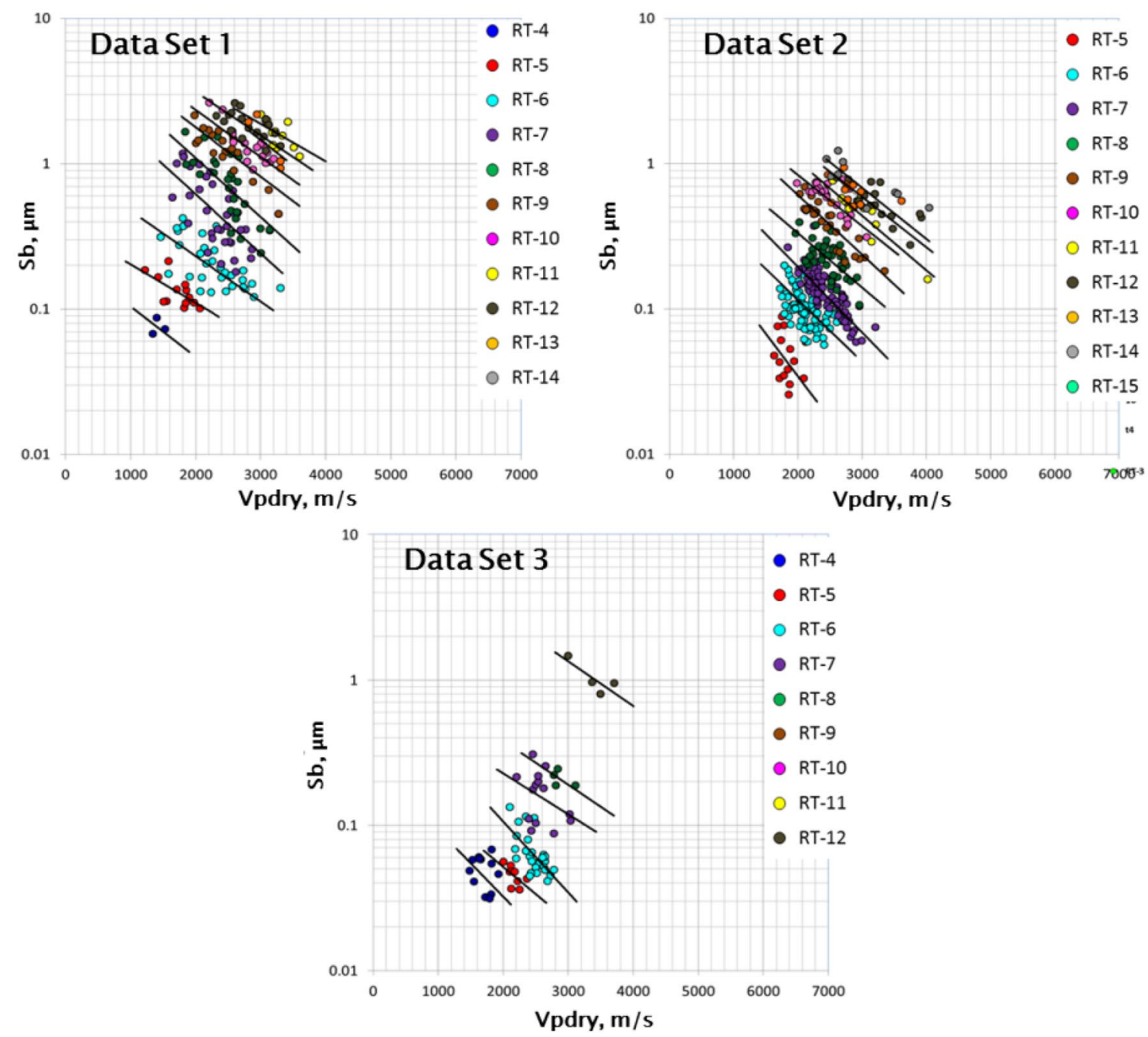

Fig. 6 Relationship between $V_{\text {pdry }}$ and specific surface area

Table 3 Value of constants $a$ and $b$ in Eq. 10 for the data sets 1,2 and 3

\begin{tabular}{|c|c|c|c|c|c|c|}
\hline \multirow{2}{*}{$\begin{array}{l}\text { Rock } \\
\text { Type }\end{array}$} & \multicolumn{2}{|c|}{ Data set 1} & \multicolumn{2}{|c|}{ Data set 2} & \multicolumn{2}{|c|}{ Data set 3} \\
\hline & $a$ & $b$ & $a$ & $b$ & $a$ & $b$ \\
\hline 4 & 0.2321 & -0.0008 & & & 0.2679 & -0.0010 \\
\hline 5 & 0.3746 & -0.0006 & 0.5143 & -0.0010 & 0.2889 & -0.0009 \\
\hline 6 & 0.972 & -0.0007 & 0.8216 & -0.0010 & 0.8006 & -0.0010 \\
\hline 7 & 4.0132 & -0.0009 & 1.5589 & -0.0010 & 0.8329 & -0.0006 \\
\hline 8 & 7.0156 & -0.0009 & 1.8662 & -0.0009 & 1.5428 & -0.0007 \\
\hline 9 & 8.4532 & -0.0008 & 4.0296 & -0.0009 & - & - \\
\hline 10 & 10.326 & -0.0007 & 4.2154 & -0.0008 & - & - \\
\hline 11 & 11.276 & -0.0006 & 5.8732 & -0.0009 & - & - \\
\hline 12 & 12.363 & -0.0007 & 6.4773 & -0.0008 & 11.2240 & -0.0007 \\
\hline 13 & 16.669 & -0.0008 & 7.3995 & -0.0009 & & \\
\hline 14 & & & 7.7684 & -0.0008 & & \\
\hline
\end{tabular}


$a$ which is the maximum value of $S_{\mathrm{b}}$ when the material turns into a suspension. The value of constant $a$ in Table 3 shows a tendency to increase with lowering quality of rock type. The lower quality of the rock type shows an increasing complexity of pore geometry and pore structure. This leads to high $S_{\mathrm{b}}$ values on critical porosity. The relationship between $S_{\mathrm{b}}$ and $V_{\mathrm{p} d r y}$ for each rock type has the same trend indicated by similar value of the slope $b$.

\section{Porosity and permeability estimation using $\boldsymbol{V}_{\text {pdry }}$}

In the previously section, it has been discussed that each rock type has similar pore geometry and pore structure which is characterized by the critical porosity value. The relationship between porosity and P-wave velocity for each rock type is limited by $\mathrm{P}$-wave velocity value of the mineral at porosity zero and zero P-wave velocity at critical porosity value that reflects a condition of suspension. Thus, the critical porosity value is the maximum porosity value in natural porous media.

The relationship between porosity and $V_{\mathrm{p} d r y}$ as shown in Fig. 3 is not linear and has shown a random distribution of data. It means that porosity estimation using linear correlation provides a low accuracy of result. Figure 3 also shows that the relationship between porosity and $V_{\mathrm{p}}$ can be well grouped based on rock type. Each rock type can be represented by 1 theoretical curve of the Nur et al. 1995, and has its own critical porosity value. The approach is used to arrange equation for porosity estimation. As it is known, P-wave velocity is a function of the bulk modulus and shear modulus (Eq. 13) as follows:

$V_{\mathrm{p}}=\sqrt{\frac{B+4 / 3 \mu}{\rho}}$

Equation 11 can be arranged in the form of modulus as follows:

$V_{\mathrm{p}}^{2} \rho=B+4 / 3 \mu$

Substitution of Eqs. 3 and 4 to Eq. 14 is used to formulate equations that can be used to estimate porosity as a function of the critical porosity and $\mathrm{P}$-wave velocity for dry condition as follows:

$\phi=\phi_{\mathrm{c}} \frac{\left(V_{\mathrm{p}}^{2} \rho-B_{\mathrm{m}}-4 / 3 \mu_{\mathrm{m}}\right)}{\left(-B_{\mathrm{m}}-4 / 3 \mu_{\mathrm{m}}\right)}$

where $V p \mathrm{~km} / \mathrm{s}, \rho$ gr/cc while $B_{\mathrm{m}}, \mu_{\mathrm{m}}$ and $\mu_{\mathrm{c}}$ in Gpa.

The assumptions used as follows:
- The rocks are composed by the dominant minerals quartz.

- Assumed that the value of bulk mineral modulus (Bm) $37 \mathrm{Gpa}$ and the shear modulus mineral $(\mu \mathrm{m})$ value 44 Gpa

Equation 15 can be used to estimate porosity using a different value of critical porosity for each rocks group. Critical porosity for each rock type can be estimated using Nur Equation as shown in Fig. 2 or Table 1. Equation 15 shows that if the value of dry P-wave velocity 0 , then the porosity is equal to the critical porosity which reflects a condition of the suspension.

Equation 15 is derived based on rock type and critical porosity. It means that porosity estimation is performed for specific rock groups that have similar pore geometry and pore structure. Thus, using Eq. 15 will obtain accurate porosity estimation results. Porosity estimation using Eq. 15 requires measurement of $V_{\mathrm{p}}$ and $V_{\mathrm{s}}$ data. The value of bulk modulus and shear modulus of mineral are assumed 37 and $44 \mathrm{Gpa}$, respectively, for quartz mineral. The critical porosity value can be simply estimated by the linear equation of Nur et al. 1995 for each rock type as shown in Fig. 2 and Table 1. Equation 15 contains information about the acoustic impedance shown in term of $V_{\mathrm{p}} \times \rho$. Thus, acoustic impedance data can be integrated directly with Eq. 15 for porosity estimation.

Furthermore, substitution of Eqs. 12 and 15 into Eq. 9 can obtain equations that can be used to estimate the permeability as a function of the $V_{\mathrm{p}}$. Equation 16 shows that P-wave velocity $\left(V_{\mathrm{p}}\right)$ is directly proportional to the permeability. This can be explained because permeability is strongly influenced by the specific surface area. Rocks with a low specific surface area tend to have large pore spaces or large hydraulic radius so that their permeability values are high. Large hydraulic radius is formed by the large grain size and tend to have a higher dry P-wave velocity $\left(V_{\mathrm{p}}\right)$. Thus, the permeability will be inversely proportional to the specific surface area but is directly proportional to the $\mathrm{P}$-wave velocity $\left(V_{\mathrm{p}}\right)$.

$k=\frac{c \phi_{c}\left(\frac{\left(V p^{2} \rho-B_{\mathrm{m}}-4 / 3 \mu_{\mathrm{m}}\right)}{\left(-B_{\mathrm{m}}-4 / 3 \mu_{\mathrm{m}}\right)}\right)^{3}}{\left(a e^{-b V p}\right)^{2}}$

where $k$ in Darcy.

In reservoir modeling, the accuracy of permeability estimation is very important because it will greatly affect the fluid flow. Equation 16 is intended to estimate permeability from $V_{\mathrm{p}}$ based on rock type. Equation 16 is arranged base on Kozeny equation (Eq. 9). The value of porosity is estimated using Eq. 15. Porosity estimation using Eq. 15 requires measurement data of $V_{\mathrm{p}}$ and $V_{\mathrm{s}}$, while the specific 

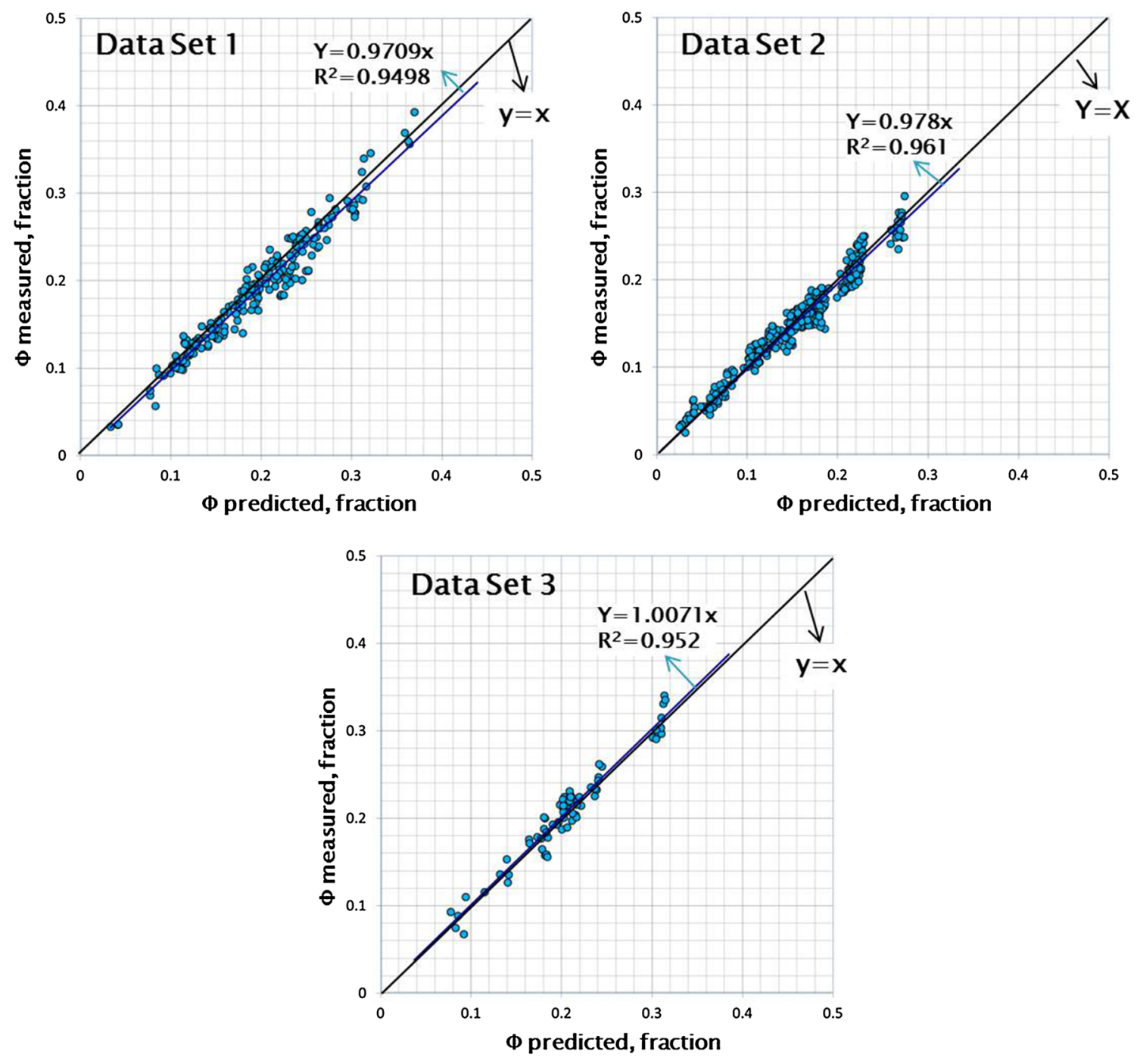

Fig. 7 Predicted versus measured porosity for data set 1,2 and 3

surface area of each rock type is estimated empirically using Eq. 12. As discussed earlier, Eq. 12 is obtained based on the relationship of $V_{\mathrm{p}}$ with $S_{\mathrm{b}}$ as shown in Fig. 2. The values of $a$ and $b$ of Eq. 12 for each rock type are shown in Table 3. The term of $V_{\mathrm{p}} \times \rho$ is usually known as acoustic impedance. Thus, if $3 \mathrm{D}$ cube acoustic impedance and $V_{\mathrm{p}}$ are available, then the permeability can easily be estimated from Eq. 16 with a good degree of accuracy.

Validation of porosity estimation results is done by comparing the porosity estimation results with the measurements of porosity (Fig. 7). Accuracy of the porosity estimation was observed based on the value of $R^{2}$ which expresses the strong relationship between the estimation results with measurements and the value of the coefficient of regression lines. $R^{2}$ values obtained are $0.9498,0.961$ and 0.952 for data set 1,2 and 3, respectively, whereas the constant of the regression line values are $0.9709,0.978$ and 1.0071 for data set 1,2 and 3, respectively. The results of the permeability estimation (Fig. 8) provide the values of $R^{2}$ are $0.9668,0.9667$ and 0.9772 for data sets 1,2 , and 3 , while the constant of regression lines are $0.9897,1.0812$ and 1.1251, whereas the exponent values of regression lines are $0.9892,0.9574$ and 0.9999 for data sets 1,2 and 3 , respectively. If both the constant and exponent values of regression lines are close to 1 , this indicates that the estimation results obtained are close to the value of the measured data.

\section{Conclusions}

Several conclusions drawn from this research are as follows: 

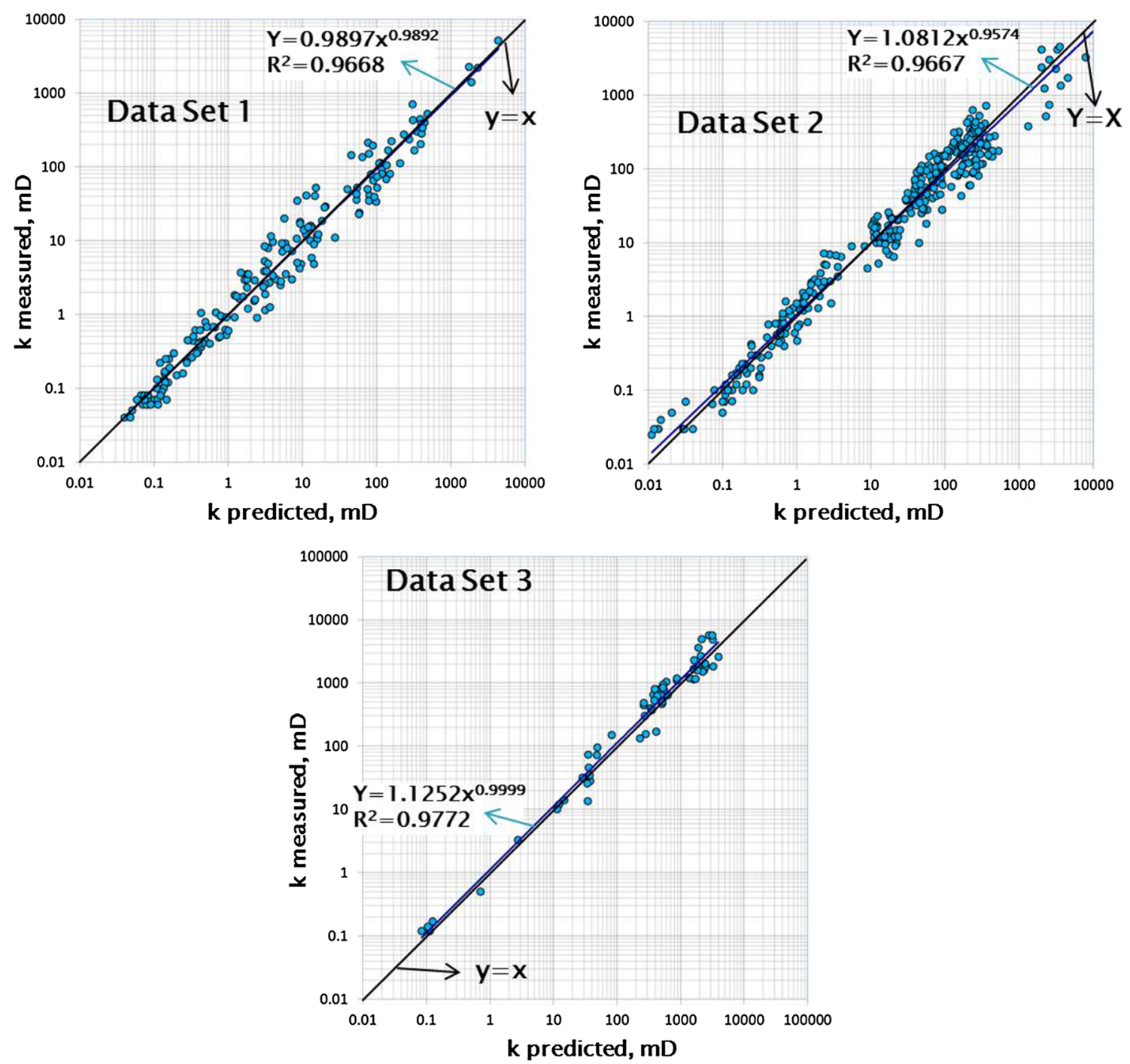

Fig. 8 Predicted versus measured permeability for data set 1,2 and 3

1. Specific relations of dry bulk modulus $\left(B_{\text {dry }}\right)$ and dry P-wave velocity $\left(V_{\mathrm{p} d r y}\right)$ to porosity are obvious when the rock samples are grouped on the basis of similarity in pore attributes, pore geometry and pore structure. This led to the results exhibiting that a critical porosity is a specific property.

2. For any given rock group, specific internal surface area increases as pore geometry in terms of mean hydraulic radii decreases, resulting in a decrease in permeability. The results show that $\mathrm{P}$-wave velocity decreases as both porosity and specific internal surface area increase. These all explain why P-wave velocity decreases with permeability but reversely with porosity.
3. Porosity and permeability of rocks can be predicted on the basis of P-wave velocity once the rock type and the corresponding critical porosity are established. For all the rock samples employed, very good results of the predicted porosity and permeability have been demonstrated.

Acknowledgments One of the authors, Suryo Prakoso, would like to thank the universitas Trisakti, Geophysical Laboratory FTKE Trisakti University for provided SonicViewer tool, and PPPTMGB "Lemigas" for the core samples and the corresponding petrography analysis data provided for his research work.

Open Access This article is distributed under the terms of the Creative Commons Attribution 4.0 International License (http://creativecommons.org/licenses/by/4.0/), which permits unrestricted use, 
distribution, and reproduction in any medium, provided you give appropriate credit to the original author(s) and the source, provide a link to the Creative Commons license, and indicate if changes were made.

\section{Appendix A}

The Voigt Bound equation for bulk modulus can be arranged by normalizing the porosity using the critical porosity as follows (Nur et al. 1995):

$B=\frac{\phi}{\phi_{\mathrm{c}}} B_{\mathrm{c}}+\left(1-\frac{\phi}{\phi_{\mathrm{c}}}\right) B_{\mathrm{m}}$

where $B$ is the bulk modulus, $B_{c}$ is the bulk modulus at critical porosity, $B_{\mathrm{m}}$ is the bulk modulus of mineral, $\phi$ is the porosity, and $\phi_{\mathrm{c}}$ is the critical porosity. The shear modulus can be written as follows (Mavko et al. 2009):

$\mu=\frac{\phi}{\phi_{\mathrm{c}}} \mu_{\mathrm{c}}+\left(1-\frac{\phi}{\phi_{\mathrm{c}}}\right) \mu_{\mathrm{m}}$

where $\mu$ is the shear modulus, $\mu_{\mathrm{c}}$ is the shear modulus at critical porosity, $\mu_{\mathrm{m}}$ is the shear modulus of mineral. P-wave velocity is a function of bulk modulus, shear modulus and density can be written as follows:

$V p=\sqrt{\frac{B+4 / 3 \mu}{\rho}}$

Equation A.3 can be written in the form of modulus as follows:

$V p^{2} \rho=B+4 / 3 \mu$

The substitution of Eqs. A.1 and A.2 into Eq. A.4 is obtained:

$$
\begin{aligned}
V p^{2} \rho= & \left(\frac{\phi}{\phi_{\mathrm{c}}} B_{\mathrm{c}}+\left(1-\frac{\phi}{\phi_{\mathrm{c}}}\right) B_{\mathrm{m}}\right) \\
& +\left(4 / 3\left(\frac{\phi}{\phi_{\mathrm{c}}} \mu_{\mathrm{c}}+\left(1-\frac{\phi}{\phi_{\mathrm{c}}}\right) \mu_{\mathrm{m}}\right)\right) \\
V p^{2} \rho= & \frac{\phi}{\phi_{\mathrm{c}}} B_{\mathrm{c}}-\frac{\phi}{\phi_{\mathrm{c}}} B_{\mathrm{m}}+4 / 3 \frac{\phi}{\phi_{\mathrm{c}}} \mu_{\mathrm{c}}-4 / 3 \frac{\phi}{\phi_{\mathrm{c}}} \mu_{\mathrm{m}}+B_{\mathrm{m}}+4 / 3 \mu_{\mathrm{m}}
\end{aligned}
$$

Furthermore, Eq. A.6 is simplified by grouping into the same variable.

$V p^{2} \rho-B_{\mathrm{m}}-4 / 3 \mu_{\mathrm{m}}=\frac{\phi}{\phi_{\mathrm{c}}}\left(B_{\mathrm{c}}-B_{\mathrm{m}}+4 / 3 \mu_{\mathrm{c}}-4 / 3 \mu_{\mathrm{m}}\right)$

Equation A.7 can be arranged for porosity estimation as a function of $V_{\mathrm{p}}$ and critical porosity as follows:

$$
\phi=\phi_{\mathrm{c}} \frac{\left(V p^{2} \rho-B_{\mathrm{m}}-4 / 3 \mu_{\mathrm{m}}\right)}{\left(B_{\mathrm{c}}-B_{\mathrm{m}}+4 / 3 \mu_{\mathrm{c}}-4 / 3 \mu_{\mathrm{m}}\right)}
$$

For dry conditions, the value of $B_{\mathrm{c}}=0$ and $\mu_{\mathrm{c}}=0$ so that Eq. A. 8 can be written as follow:

$\phi=\phi_{\mathrm{c}} \frac{\left(V p^{2} \rho-B_{\mathrm{m}}-4 / 3 \mu_{\mathrm{m}}\right)}{\left(-B_{\mathrm{m}}-4 / 3 \mu_{\mathrm{m}}\right)}$

with $V_{\mathrm{p}}$ in $\mathrm{km} / \mathrm{s}, \rho$ in $\mathrm{gr} / \mathrm{cc}$, whereas $B_{\mathrm{m}}, \mu_{\mathrm{m}}$ and $\mu_{\mathrm{c}}$ in Gpa.

Equation A. 8 is then combined with the Kozeny equation to obtain the permeability equation as a function of $V_{\mathrm{p}}$ and critical porosity. Modification of Kozeny equation is done by substitution of Eqs. 12-9 to obtain the following equation:

$k=0.9869 \frac{c \phi^{3}}{\left(a e^{b(V p x 1000)}\right)^{2}}$

where $k$ in Darcy and $V_{\mathrm{p}}$ in $\mathrm{km} / \mathrm{s}$. Equation A.8 is substituted to Eq. A.10 to obtain the permeability equation as function of $V_{\mathrm{p}}$ as follows:

$k=0.9869 \frac{c\left(\phi_{\mathrm{c}} \frac{\left(V p^{2} \rho-B_{\mathrm{m}}-4 / 3 \mu_{\mathrm{m}}\right)}{\left(B_{\mathrm{c}}-B_{\mathrm{m}}+4 / 3 \mu_{\mathrm{c}}-4 / 3 \mu_{\mathrm{m}}\right)}\right)^{3}}{\left(a e^{b(V p x 1000)}\right)^{2}}$

For dry conditions, the value of $B_{\mathrm{c}}=0$ and $\mu_{\mathrm{c}}=0$ so that Eq. A.11 can be written as follows:

$k=0.9869 \frac{c\left(\phi_{c} \frac{\left(V p^{2} \rho-B_{\mathrm{m}}-4 / 3 \mu_{\mathrm{m}}\right)}{\left(-B_{\mathrm{m}}-4 / 3 \mu_{\mathrm{m}}\right)}\right)^{3}}{\left(a e^{b^{\prime}(V p x 1000)}\right)^{2}}$

where k in Darcy, $V_{\mathrm{p}}$ in $\mathrm{km} / \mathrm{s}, \rho$ in gr/cc while $B_{\mathrm{m}}$ and $\mu_{\mathrm{m}}$ are in Gpa, while $a$ and $b$ are empirical constants of Eq. 12 as shown in Table 1.

\section{References}

El-Khatib N (1995) Development of a modified capillary pressure-J function. In: Paper SPE 29890 presented at the SPE Middle East Oil Show held in Bahrain: March 11-14, 1995

Fabricius IL, Baechle G, Eberli GP, Weger R (2007) Estimating permeability of carbonate rocks from porosity and Vp/Vs. Geophysics 72:5. https://doi.org/10.1190/1.2756081

Han DH, Nur A, Morgan D (1986) Effects of porosity and clay content on wave velocities in sandstones. Geophysics 51:20932107. https://doi.org/10.1190/1.1442062

Klimentos T (1991) The effects of porosity-permeability-clay content on the velocity of compressional waves. Geophysics 56(12):1930-1939. https://doi.org/10.1190/1.1443004

Kozeny J (1927) Uber kapillare leitung des wassers im boden (Aufstieg Versikerung und Anwendung auf die Bemasserung), Sitzungsber Akad, Wiss, Wein, Math-Naturwiss, KL 136(Ila): 271-306

Mavko G, Mukerji T, Dvorkin J (2009) The rock physics handbook, 2nd edn. Cambridge University, Cambridge 
Mortensen J, Engstrom F, Lind I (1998) The relation among porosity, permeability and specific surface of chalk from the gorm field. Danish North Sea, SPE

Nur A, Mavko G, Dvorkin J, Gal D (1995) Critical porosity: the key to relating physical properties to porosity in rocks. In Proceedings of 65th Annual International Meeting of Society of Exploration Geophysicists, vol 878, Tulsa. https://doi. org/10.1190/1.1887540

Prakoso S, Permadi P, Winardhie S (2016) Effects of pore geometry and pore structure on dry P-wave velocity. Modern Appl Sci 10(8):117-133. https://doi.org/10.5539/mas.v10n8p117

Prasad M (2003) Velocity-permeability relations within hydraulic units. Geophysics 68:108-117. https://doi. org/10.1190/1.1543198

Raymer LL, Hunt ER, Gardner JS (1980) An improved sonic transit time-to-porosity. In: SPWLA ninth annual logging symposium
Weger RJ, Eberli GP (2009) Quantification of pore structure and its effect on sonic velocity and permeability on carbonate. AAPG Bull 93(10):1297-1317. https://doi.org/10.1306/05270909001

Wibowo AS (2014) Karakterisasi Batuan Karbonat Berdasarkan Geometri dan Struktur Pori-Pori. Doctoral dissertation, Institut Teknologi Bandung, Indonesia

Wibowo AS, Permadi P (2013) A type curve for carbonates rock typing. Int Petrol Technol Conf. https://doi.org/10.2523/IPTC-16663-MS

Wyllie MRJ, Gregory AR, Gardner IW (1956) Elastic wave velocities in and porous media. Geophysics 12(1):41-70

Publisher's Note Springer Nature remains neutral with regard to jurisdictional claims in published maps and institutional affiliation. 